\title{
Surface-bound myeloperoxidase is a ligand for recognition of late apoptotic neutrophils by human lung surfactant proteins $A$ and $D$
}

\author{
Anne Jäkel ${ }^{1,3}$, Howard Clark ${ }^{2,3}$, Kenneth B. M. Reid ${ }^{3}$, Robert B. Sim ${ }^{1,3 \bowtie}$ \\ ${ }^{1}$ Department of Pharmacology, University of Oxford, Mansfield Road, Oxford OX1 3QT, UK, \\ ${ }^{2}$ University of Southampton, School of Medicine, Division of Infection Inflammation \& Immunity, Southampton General Hospital, \\ Southampton SO16 6YD, UK \\ ${ }^{3}$ MRC Immunochemistry Unit, Department of Biochemistry, University of Oxford, South Parks Road, Oxford OX1 3QU, UK \\ \ Correspondence: bob.sim@bioch.ox.ac.uk \\ Received April 21, 2010 Accepted May 28, 2010
}

\begin{abstract}
Surfactant proteins A (SP-A) and D (SP-D), both members of the collectin family, play a well established role in apoptotic cell recognition and clearance. Recent in vitro data show that SP-A and SP-D interact with apoptotic neutrophils in a distinct manner. SP-A and SP-D bind in a $\mathrm{Ca}^{2+}$-dependent manner to viable and early apoptotic neutrophils whereas the much greater interaction with late apoptotic neutrophils is $\mathrm{Ca}^{2+}$-independent. Cell surface molecules on the apoptotic target cells responsible for these interactions had not been identified and this study was done to find candidate target molecules. Myeloperoxidase (MPO), a specific intracellular defense molecule of neutrophils that becomes exposed on the outside of the cell upon apoptosis, was identified by affinity purification, mass-spectrometry and western blotting as a novel binding molecule for SP-A and SP-D. To confirm its role in recognition, it was shown that purified immobilised MPO binds SP-A and SP-D, and that MPO is surface-exposed on late apoptotic neutrophils. SP-A and SP-D inhibit binding of an anti-MPO monoclonal $A b$ to late apoptotic cells. Fluorescence microscopy confirmed that anti-MPO mAb and SP-A/SP-D colocalise on late apoptotic neutrophils. Desmoplakin was identified as a further potential ligand for SP-A, and neutrophil defensin as a target for both proteins.
\end{abstract}

KEYWORDS SP-A, SP-D, myeloperoxidase, neutrophils, flow cytometry, mass spectrometry

\section{INTRODUCTION}

Apoptosis is regarded as the process of programmed cell death, in which the rearrangement of plasma-membrane components, including proteins and phospholipids mark the apoptotic cell as a target for the binding of innate immune system proteins and subsequently for phagocytic clearance. Clearance of apoptotic cells is an important step in the resolution of the inflammatory response, as well as in normal growth and development during embryogenesis (Fadok and Henson, 2003). As apoptosis progresses, the integrity of the plasma membrane is lost, resulting in leakage of potentially toxic intracellular contents into the environment and triggering of an inflammatory response (Fadok and Chimini, 2001).

Efficient clearance of dying cells may be particularly important in the lung in which immune challenges occur regularly, sometimes eliciting the influx of massive numbers of inflammatory cells. Recognition and clearance of apoptotic cells are accomplished by a redundant system of phagocyte receptors (Fadok et al., 2001; Ogden et al., 2001; Somersan and Bhardwaj, 2001), soluble bridging molecules (Somersan and Bhardwaj, 2001), and apoptotic cell ligands (Fadok et al., 1992; Somersan and Bhardwaj, 2001). Evidence indicates that two members of the collectin family, surfactant protein $A$ (SP-A) and surfactant protein D (SP-D), participate in apoptotic cell removal by alveolar macrophages in vitro (Schagat et al., 2001).

The collectins, including SP-A and SP-D, are part of the innate immune system and are thought to be primarily important in host defense because of their capability 
specifically to recognize pathogens and facilitate their removal through opsonin-mediated phagocytosis. Collectins are oligomeric proteins characterized by $\mathrm{N}$-terminal collagenlike domains and $\mathrm{C}$-terminal lectin or carbohydrate binding domains (Holmskov et al., 1994). Family members are pattern recognition molecules that bind nonself moieties, thereby targeting the foreign material for rapid clearance by immune cells. SP-A in particular can bind to a variety of substrates, including carbohydrates, surfactant lipids and lipid vesicles (Haagsman et al., 1990; Haagsman et al., 1991; Kuroki and Akino, 1991; Jäkel et al., 2010) and proteins (myosin) (Michelis et al., 1994). Binding of SP-A to both bacteria and lipid vesicles enhances their phagocytosis by macrophages (Gaynor et al., 1995; Wright and Youmans, 1995; Tino and Wright, 1999).

Several in vivo models of pulmonary injury demonstrate the importance of alveolar macrophage (AM) phagocytosis of apoptotic granulocytes in the resolution of inflammation (Cox et al., 1995; Hussain et al., 1998), and it has been suggested that chronic pulmonary inflammation may be a result of inefficient clearance of apoptotic granulocytes (Haslett, 1999).

Recent data imply a distinct role of SP-A and SP-D in the recognition of apoptotic cells. Jäkel and coworkers (Jäkel et al., 2010) show that SP-A and SP-D interact with late apoptotic Jurkat cells and neutrophils in a $\mathrm{Ca}^{2+}$-independent manner whereas the binding to viable and early apoptotic target cells for SP-A was $\mathrm{Ca}^{2+}$-dependent and inhibited by mannose (for both cell types). SP-D did not interact with viable and early apoptotic Jurkat cells at all but bound in a mixed mode $\left(\mathrm{Ca}^{2+}\right.$-dependent or-independent) to viable and early apoptotic neutrophils. However, in these studies it was not investigated which surface molecules on the apoptotic target cell were involved in this association. In the present study, the binding of SP-A and SP-D to neutrophil proteins was investigated. Here we report the identification of myeloperoxidase (MPO) by affinity selection, mass spectrometry and western blotting as a novel SP-A and SP-D binding molecule on the late apoptotic cell. Flow cytometry data show MPO is exposed on the cell surface, and that SP-A and SP-D both inhibit the binding of an anti-MPO specific mAb to the surface of late apoptotic cells. These findings were confirmed by fluorescence microscopy showing colocalization of SP-A/ SP-D and anti-MPO mAb. Thus, we conclude that SP-A and SP-D interact with MPO on the surface of late apoptotic neutrophils. Neutrophil defensin and desmoplakin were also indentified as potential target proteins.

\section{RESULTS}

\section{Identification of MPO as a binding molecule for SP-A and SP-D}

Streptavidin-activated magnetic beads were coated with biotinylated SP-A and SP-D and incubated with cell lysates of viable, early and late apoptotic neutrophils in a $\mathrm{CaCl}_{2}-$ containing buffer in order to enrich putative target proteins which might interact with the lung collectins. As a background control, streptavidin-activated beads without SP-A or SP-D were also incubated with the cell supernatant and compared with the SP-A and SP-D coated beads.

After washing, bound proteins were eluted with $1 \mathrm{mM}$ EDTA and subsequently with citric acid, $\mathrm{pH} 2.5$. Eluted fractions were analyzed by SDS-PAGE followed by silver staining. Bands visible on the gel, corresponding to putative receptor candidates, were submitted for analysis by mass spectrometry.

Independently of the stage of cell viability, the pattern of enriched protein bands was very similar for SP-A (Fig. 1A), showing five distinct bands (labeled 1-5), two of which eluted in EDTA (bands 1 and 2) and the rest in acid.

This suggested that during entry into cell death no additional SP-A binding proteins were expressed. There were no protein bands visible with the blank beads, showing that the washing procedure did not leave any non-specifically bound proteins on the beads.

The pattern of proteins eluted from SP-D coated beads (Fig. 1B) also showed no difference between stages of cell viability. The proteins eluted in acid (tracks 4) were very similar to those eluted from SP-A coated beads, such that the major bands (labeled $6,7,8$ ) appear to be the same as the major bands (labeled $3,4,5$ ) eluted from SP-A coated beads (Fig. 1A, tracks 4). A striking difference, however, is that no proteins were eluted from the SP-D coated beads in EDTA (Fig. 1B, tracks 2). Thus, bands 1 and 2 (Fig. 1A, tracks 2) bind only to SP-A.

The molecular weights (MW) of the isolated protein bands were calculated in a $\log _{M W}$ versus mobility plot of the protein standard (Weber and Osborn, 1969). For SP-A coated beads only, two prominent protein bands of $>200 \mathrm{kDa}$ and $\sim 20 \mathrm{kDa}$ were seen which eluted with EDTA (Fig. 1A, bands 1, 2), suggesting a calcium ion-dependent binding mechanism of SP-A. These gel bands were submitted for identification by mass spectrometry analysis. For SP-D coated beads, no calcium-dependent binding proteins were seen (Fig. 1B).

For SP-A beads, the elution pattern of the low $\mathrm{pH}$ buffer (Fig. 1A) showed several protein bands, which are candidates for the non- $\mathrm{Ca}^{2+}$-dependent binding of SP-A. The three strongest bands running at $60 \mathrm{kDa}$ (band 3 ), $15 \mathrm{kDa}$ (band 4) and $5 \mathrm{kDa}$ (band 5) in SDS-PAGE were submitted for identification by mass spectrometry analysis. These were assumed to be the same as bands $6,7,8$, respectively, eluted from the SP-D coated beads (Fig. 1B).

Protein identification by mass spectrometry revealed the presence of five candidate proteins (Table 1). The protein identified in band 1 , is desmoplakin, which belongs to a group of molecules which are involved in the formation of desmosomes, the major intercellular junctions of epithelial cells 


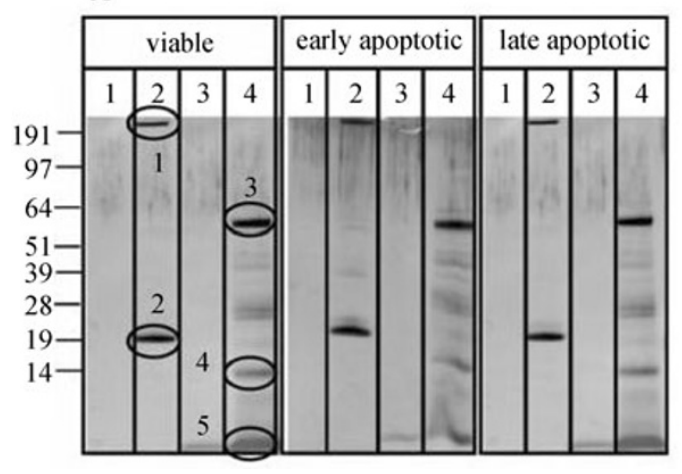

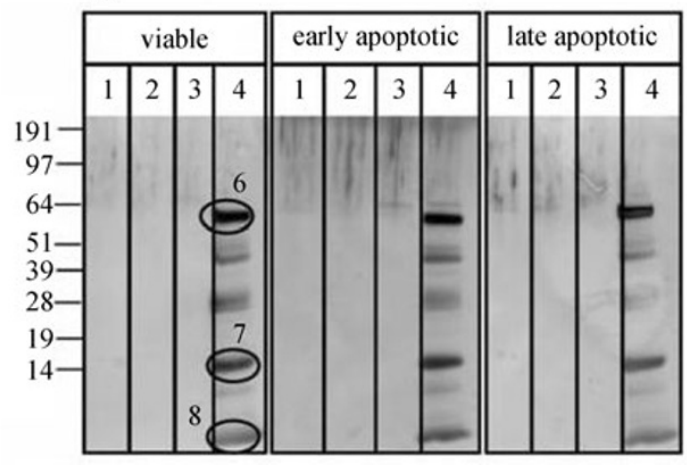

Figure 1. Interactions of SP-A and SP-D with proteins in neutrophil lysates. Cell lysates of viable, early apoptotic and late apoptotic neutrophils were generated and incubated with (A) SP-A- or (B) SP-D-coated magnetic beads. After washing, bound proteins were eluted with $1 \mathrm{mM}$ EDTA followed by $100 \mathrm{mM}$ citric acid, $\mathrm{pH}$ 2.5. Elution patterns are shown in SDS-PAGE (reduced conditions): 1, blank beads (without SP-A or SP-D) eluted with EDTA; 2, SP-A or SP-D beads eluted with EDTA; 3 , blank beads eluted with citric acid; 4, SP-A or SP-D beads eluted with citric acid. Bands circled (1)-(8) were processed for mass spectrometry analysis for identification.

(Kowalczyk et al., 1999). The molecular weight of desmoplakin is consistent with its running position at the top of the gel (Fig. 1A). It was not excluded as a candidate binding protein as it shows a relatively high protein score (Table 1). However, western blot analysis performed as described for MPO (Fig. 2) but using $10 \mu \mathrm{g} / \mathrm{mL}$ anti-desmoplakin $1+2 \mathrm{mAb}$ (AbD Serotec, Abingdon, UK) failed to confirm the presence of desmoplakin. A cell lysate of HeLa cells was positive in this assay.

Band 2 (Fig. 1A) was not identified satisfactorily. Two peptide matches to IgG3 heavy chain were noted but with a low score. Band 2 may be a fragment $(20 \mathrm{kDa})$ of a human IgG3 (heavy chain $50 \mathrm{kDa}$ ), which may have reacted with some feature of the biotinylated proteins or their adduct with the beads.

Band $3(60 \mathrm{kDa})$ matches well with the identification of myeloperoxidase (MPO) (very high protein score), with two heavy $(60 \mathrm{kDa})$ and two light chains $(15 \mathrm{kDa})$. This protein seems to be a strong candidate as band $4(15 \mathrm{kDa})$ was also identified as MPO, so both heavy and light chains are present. The elution was not in EDTA, but at low $\mathrm{pH}$, indicating that the interaction with SP-A is not $\mathrm{Ca}^{2+}$-dependent.

The presence of MPO in the acidic eluates of beads coated with SP-A and SP-D was confirmed by western blotting (Fig. 2). For both proteins, the presence of MPO was shown in viable, early and late apoptotic cell lysates.

MPO (Swiss Protein number P05164) is a dimer of 2 disulfide-linked heavy chains ( $60 \mathrm{kDa}$, amino acids 279-745) non-covalently linked to two light chains ( 15 kDa, amino acids 165-278). The mAb appears to recognize both heavy and light chain. This has been observed previously (Audrain et al., 1997). Sequence similarity suggests there may be common epitope(s), e.g., EPLAR (heavy chain) and EPAAR (light chain).

Neutrophil defensin 1 was identified in band 5 ( $5 \mathrm{kDa})$ with five peptide matches. The presence of defensin in this band was confirmed by western blotting using $10 \mu \mathrm{g} / \mathrm{mL}$ antiadefensin 1+2+3 mAb (Abcam, Cambridge, UK).

\section{SP-A and SP-D bind MPO in ELISA}

To confirm the interaction of SP-A and SP-D with isolated,

Table 1 Identification of putative receptors of SP-A and SP-D on neutrophils by mass spectrometry. Band numbers indicate protein bands submitted to mass spectrometry analysis (Fig. 1). Numbers of peptide matches, protein scores and mass calculation were obtained from mass spectrometry data.

\begin{tabular}{lccccc}
\hline band number & $\begin{array}{c}\text { molecular weight (on } \\
\text { SDS-PAGE) }(\mathrm{kDa})\end{array}$ & protein name & peptide matches & protein score & $\begin{array}{c}\text { mass calculation } \\
(\mathrm{kDa})\end{array}$ \\
\hline 1 & off scale & desmoplakin & 9 & 77 & 334 \\
2 & 20 & $\begin{array}{c}\text { FLJ00385 (fragment) } \\
\text { (lgG heavy chain 3) }\end{array}$ & 2 & 36 & 57 \\
3 & 60 & myeloperoxidase & 7 & 128 & $60+15$ \\
4 & 15 & myeloperoxidase & 5 & 50 & $60+15$ \\
5 & 5 & neutrophil defensin 1 & 5 & 34 & 10 \\
\hline
\end{tabular}




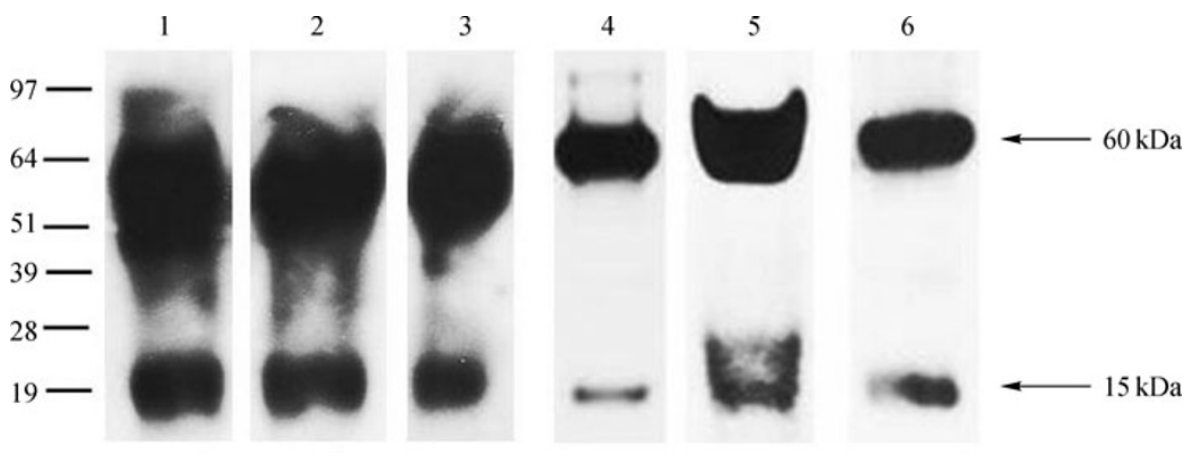

Figure 2. Western Blot analysis for the detection of neutrophil MPO. SP-A (lanes 1-3) or SP-D (lanes 4-6) coated magnetic beads were incubated with neutrophil lysates from viable (lanes 1, 4), early apoptotic (lanes 2, 5) and late apoptotic cells (lanes 3,6). After washing, beads were eluted with citric acid, $\mathrm{pH} 2.5$ and run on SDS-PAGE (reducing conditions). Protein bands were analyzed by western blotting using monoclonal anti-MPO Ab and HRP-conjugated rabbit anti-mouse polyclonal antibody. MPO runs in two characteristic bands at $60 \mathrm{kDa}$ and $15 \mathrm{kDa}$.

immobilised MPO, an ELISA was performed. MPO was coated onto microtiter plates and incubated with SP-A and SP-D in the presence of $\mathrm{CaCl}_{2}$ or EDTA. Binding was detected with specific mAbs against SP-A or SP-D. Data show that SP-A (Fig. 3A) and SP-D (Fig. 3B) bind to MPO in a concentration-dependent manner. This interaction appeared to be $\mathrm{Ca}^{2+}$-independent.

\section{MPO appears on the surface of late apoptotic neutrophils}

To detect in which stage of viability MPO is expressed on the outside of the cell, and can therefore be a target for SP-A or SP-D binding, a flow cytometry-based binding assay was performed. Viable, early apoptotic and late apoptotic neutrophils were incubated with anti-MPO mAb in a $\mathrm{CaCl}_{2}$ containing buffer. Binding was detected with FITC-labeled rabbit anti-mouse IgG. Data in Fig. 4 show that viable and early apoptotic neutrophils do not show exposure of MPO on the cell surface as judged by the mean fluorescence intensity (MFI, 19 and 20 for viable and early apoptotic cells, respectively). In contrast, late apoptotic cells show an increase in MFI (63), showing increased expression of MPO on the cell surface. These results confirm the findings of Flemmig et al. (2008), indicating that MPO becomes increasingly exposed on the cell surface of neutrophils as the cells undergo apoptosis.

\section{SP-A and SP-D inhibit the binding of anti-MPO mAbs to late apoptotic neutrophils}

This flow cytometry based inhibition assay was performed to examine whether SP-A and SP-D binding can block the epitope on the cell surface recognized by the $\mathrm{mAb}$ directed against MPO. Late apoptotic neutrophils were simultaneously incubated with anti-MPO mAbs and different concentrations of unlabelled SP-A or SP-D.

Results show that for both SP-A and SP-D the binding of anti-MPO is inhibited with increased concentration of SP-A or SP-D (Fig. 5). For both proteins, $30 \mu \mathrm{g}$ led to complete inhibition of anti-MPO binding (Fig. 5 (e)).
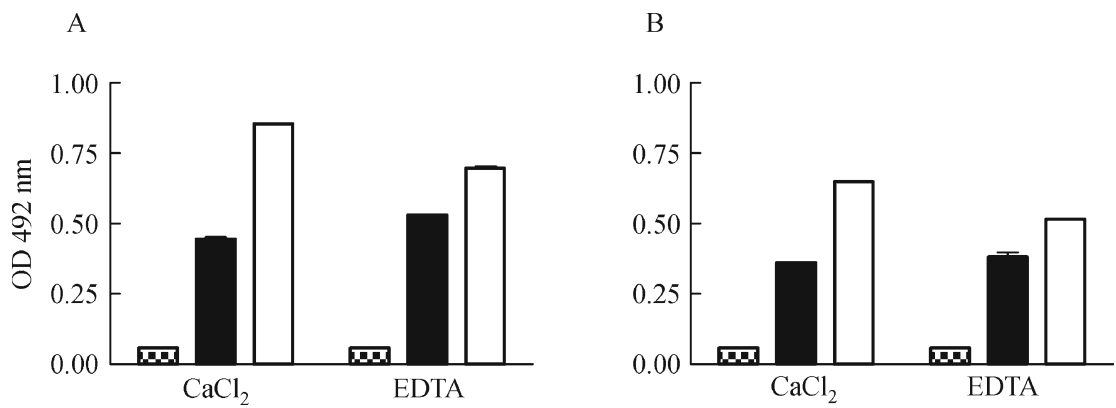

Figure 3. ELISA showing binding of SP-A and SP-D to neutrophil MPO. MPO was coated onto microtiter plates and incubated with $10 \mu \mathrm{g} / \mathrm{mL}$ (black bars) or $20 \mu \mathrm{g} / \mathrm{mL}$ (white bars) SP-A (A) or SP-D (B) in the presence of $\mathrm{CaCl}_{2}$ or EDTA, followed by incubation with biotinylated anti-SP-A or anti-SP-D mAb and streptavidin-HRP. Signal was detected at $492 \mathrm{~nm}$. Dotted bars indicate negative control (instead of SP-A or SP-D, BSA was used). 


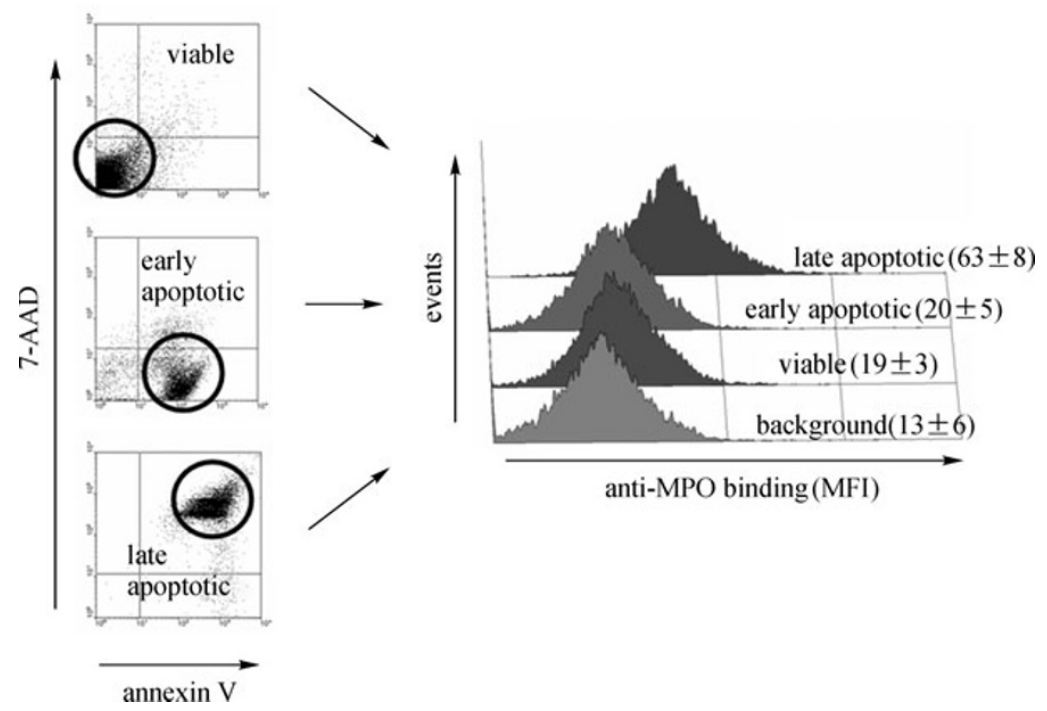

Figure 4. Exposure of MPO on late apoptotic neutrophils. Viable, early apoptotic and late apoptotic neutrophils were incubated with anti-MPO mAb followed by incubation with annexin V-PE, 7-AAD and FITC-labeled rabbit anti-mouse antibody. Binding was measured by flow cytometry. Cell populations were identified according to annexinV and 7-AAD characteristics. Numbers in brackets indicate the mean fluorescence $(\mathrm{MFI})$ of samples \pm standard deviation. Background controls were late apoptotic Jurkat cells.
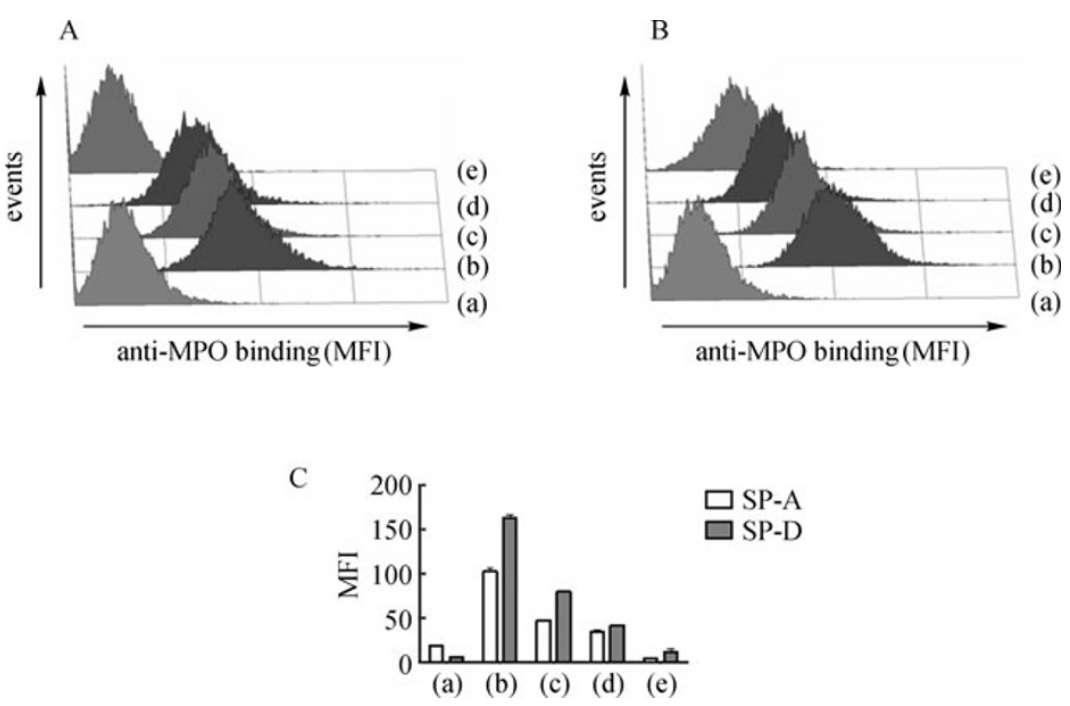

Figure 5. Inhibition of anti-MPO binding by SP-A or SP-D on late apoptotic neutrophils. Late apoptotic neutrophils were incubated with different concentrations of unlabelled SP-A $(A, 0-30 \mu \mathrm{g})$ or SP-D $(B, 0-30 \mu \mathrm{g})$ and anti-MPO mAb $(1 \mu \mathrm{g} / \mathrm{mL})$ in the presence of $\mathrm{CaCl}_{2}$ in a total volume of $50 \mu \mathrm{L}$. Samples were subsequently labeled with annexin V-PE, 7-AAD and FITC-labeled rabbit anti-mouse antibody in the presence of $\mathrm{CaCl}_{2}$. (a) Background control (late apoptotic Jurkat cells without SP-A or SP-D), (b) late apoptotic neutrophils without SP-A or SP-D, or with (c) $10 \mu \mathrm{g}$ SP-A or SP-D, or with (d) $20 \mu \mathrm{g}$ SP-A or SP-D, or with (e) $30 \mu \mathrm{g}$ SP-A or SP-D. Binding was measured by flow cytometry. MFI indicates mean fluorescence intensity. (C) Bar diagram showing the MFI for inhibition of antibody binding by SP-A and SP-D as taken from histogram data (Fig. 5A and 5B). Late apoptotic cells were identified as described previously (Jäkel et al., 2009).

\section{SP-A and SP-D colocalize with anti-MPO mAbs on late apoptotic neutrophils}

Studies on SP-A and SP-D binding in the presence of antiMPO mAbs were performed on late apoptotic neutrophils in
EDTA and $\mathrm{CaCl}_{2}$. The binding was examined by fluorescence microscopy. As seen in Fig. 6, anti-MPO mAb bound strongly to the cells. This occurred in EDTA and $\mathrm{CaCl}_{2}$. The binding of SP-A and SP-D to late apoptotic cells showed relatively weak fluorescence. Previous results showed strong binding to late 
apoptotic neutrophils (Jäkel et al., 2010), but in the present binding assay biotinylated proteins were used in comparison to specific mAbs in the published results. The differences are likely to be due to biotinylation status of the proteins. The merged images show overlap of binding of SP-A or SP-D and of the anti-MPO mAb. Binding of mAb and collectins occurred both in the presence of EDTA and calcium ions. This confirms the findings of the ELISA data, showing binding of SP-A and SP-D to MPO in both $\mathrm{CaCl}_{2}$ and EDTA and confirms previous results (Jäkel et al., 2009), indicating a non-calcium dependent binding of collectins to late apoptotic cells.

\section{DISCUSSION}

Recent evidence shows that SP-A and SP-D interact with apoptotic target cells in a very distinct manner (Jäkel et al., 2010). SP-A bound to viable and early apoptotic cells predominantly $\mathrm{Ca}^{2+}$-dependently but the interaction with late apoptotic cells was much greater and was $\mathrm{Ca}^{2+}$-independent, suggesting involvement of sites on SP-A other than the lectinor $\mathrm{Ca}^{2+}$-binding sites. This was consistent for neutrophils and Jurkat cells.

SP-D in contrast, did not interact with viable and early apoptotic Jurkat cells but strongly and in a $\mathrm{Ca}^{2+}$-independent manner with late apoptotic Jurkat cells. SP-D binding to viable and early apoptotic neutrophils was inhibited by maltose and EDTA, suggesting lectin binding site involvement whereas the binding to late apoptotic neutrophils was predominantly $\mathrm{Ca}^{2+}$ - independent. However, the surface molecules involved in these interactions were not identified in the previous study (Jäkel et al., 2010).

In the present study, we show that MPO is a novel non-Ca ${ }^{2+}$. dependent binding molecule on the surface of late apoptotic cells for SP-A and SP-D.

The haem protein myeloperoxidase (MPO) is stored in large amounts in azurophilic granules present in granulocytes and is assumed to play an important role in pathogen defense by generation of halogenated products and other oxidants (Klebanoff, 1991). Recently, it has been shown that MPO adheres tightly to phosphatidylserine (PS) epitopes on the surface of apoptotic spermatozoa, while no binding of MPO occurred to vital cells (Lessig et al., 2007). It was also demonstrated that MPO can be found on the surface of apoptotic neutrophils in close association with PS epitopes (Flemmig et al., 2008).

The present data demonstrate that the lung collectins SP-A and SP-D vary in their binding behavior to proteins derived from neutrophils since their overall binding patterns showed some differences (Fig. 1). The comparison of protein bands obtained from neutrophil cell lysates shows that the elution pattern of the EDTA eluate for SP-A and SP-D is different as there were no protein bands recovered from neutrophils for SP-D. In contrast to that, the protein bands derived from the low $\mathrm{pH}$ eluate for SP-A and SP-D were very similar in their MW spectrum, suggesting that these bands most likely represent the same proteins.

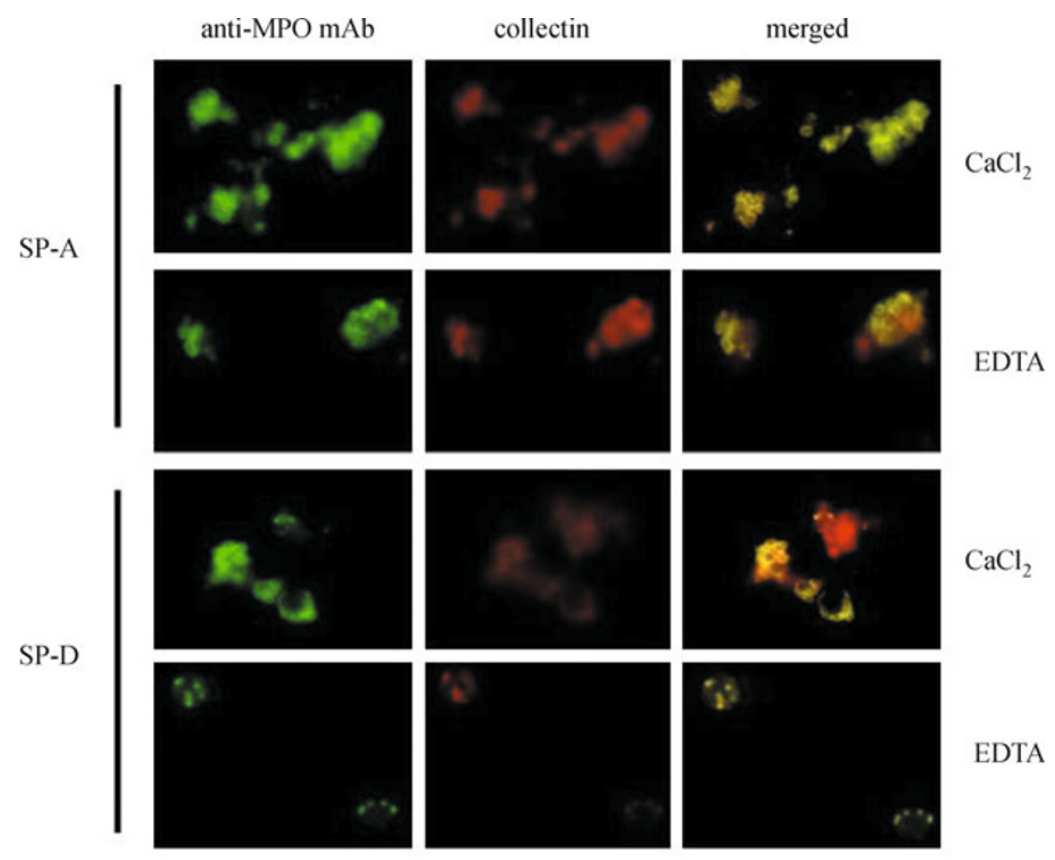

Figure 6. Fluorescence microscopic image of co-localization of collectins and anti-MPO mAb on the surface of late apoptotic neutrophils. Late apoptotic neutrophils were simultaneously incubated with biotinylated SP-A or SP-D and anti-MPO $\mathrm{mAb}$, followed by simultaneous incubation with streptavidin-PE and FITC labeled rabbit anti-mouse IgG. Buffer conditions were $\mathrm{CaCl}_{2}$ or EDTA. 
The identification of MPO heavy and light chain by mass spectrometry and western blotting in two gel bands and the high protein score suggest that identification of this protein as a ligand for SP-A and SP-D is reliable.

MPO appears on the surface of late apoptotic cells (Fig. 4) and the direct binding of SP-A and SP-D to MPO was demonstrated and was not $\mathrm{Ca}^{2+}$-dependent (Fig. 3). MPO is likely to contribute to the recognition of late apoptotic cells by SP-A and SP-D (Jäkel et al., 2010). MPO might play a role of a bridging molecule between PS epitopes on apoptotic cells and SP-A, and facilitates in this way the internalisation of apoptotic cells by macrophages.

Other molecules identified in the present study include neutrophil defensin 1 and desmoplakin. No interactions of desmoplakins with the lung collectins have been reported before. The mass spectrometry data however were not confirmed by western blotting. Whether desmoplakin is indeed a binding molecule for SP-A and SP-D remains to be investigated further. However, desmoplakin is likely to be synthesized by neutrophils as mRNA for an associated intercellular junction-forming protein, plakoglobin, has been detected in granulocytes of healthy donors (Tonks et al., 2007).

Interactions of neutrophil defensins with SP-D were described by Hartshorn et al. (2006). In that study, human neutrophil defensins were found to bind to the neck and/or carbohydrate recognition domain (CRD) region of SP-D in a $\mathrm{Ca}^{2+}$-independent manner. Also, neutrophil defensins precipitated SP-D from broncho-alveolar lavage fluid (BALF) and reduced the antiviral activity of BALF against Influenza $A$ virus.

In summary, our data show that MPO is a strong candidate binding target which mediates interaction of SP-A and SP-D to late apoptotic neutrophils. Desmoplakin and neutrophil defensin are also possible candidates, but further data on their localization on the surface of apoptotic neutrophils would be required to confirm that they are real targets.

\section{MATERIALS AND METHODS}

All chemicals used were purchased from Sigma (St. Louis, MO, USA) unless otherwise indicated. Biotinylated anti-human SP-A and antihuman SP-D monoclonal antibodies were obtained from Antibodyshop (Gentofte, Denmark). 7-amino-actinomycin D (7-AAD) solution was purchased from BD Pharmingen (Cat \#51-68981E, San Diego, CA, USA). FITC-labeled annexin V solution (Cat \#31490013) and phycoerythrin (PE)-labeled streptavidin solution (Cat \#31274244) were obtained from Immunotools (Friesoythe, Germany).

\section{Protein purification}

Native human SP-D and native human SP-A were purified from bronchiolar lavage fluid (BALF) obtained from alveolar proteinosis patients as described previously (Suwabe et al., 1996; Strong et al., 1998). Purity of the proteins was verified by SDS-PAGE analysis and was $>95 \%$. The purified proteins were dialysed into $20 \mathrm{mM}$ Tris,
$150 \mathrm{mM} \mathrm{NaCl}, \mathrm{pH} 7.4$ (TBS) and concentrated up to $1 \mathrm{mg} / \mathrm{mL}$ using Amicon filter units (cut off $100 \mathrm{kDa}$, Amicon, Denver, CO, USA).

Purified proteins were treated to remove endotoxin by passing the protein solutions through a 10-mL Polymyxin B column (Pierce, Rockford, IL, USA) in sterile TBS plus $0.02 \%(w / v)$ sodium azide, $\mathrm{pH}$ 7.4. Remaining levels of endotoxin were assayed using a Limulus Amoebocyte Lysate kit, according to the manufacturer's instructions (Biowhittaker). An endotoxin level of $<10 \mathrm{pg} / \mathrm{\mu g}$ of protein was judged acceptable to use in cell-based assays.

\section{Isolation of neutrophils and induction of apoptosis}

Human neutrophils were isolated from venous blood from consenting healthy volunteers as previously described (Jäkel et al., 2009). Spontaneous apoptosis was achieved by incubation of the cells over a time course of $0-48 \mathrm{~h}$ at $37^{\circ} \mathrm{C}, 5 \% \mathrm{CO}_{2}$ and $95 \%$ humidity. Early and late apoptosis was confirmed by flow cytometry as previously described (Jäkel et al., 2009) by assessing annexin $V$ binding and 7-AAD incorporation into the cells.

\section{Statistical analysis}

All data are expressed as the mean \pm standard error of the mean (SEM) and were plotted with Graph Pad Prism Software (GraphPad Software Inc., La Jolla, CA, USA).

\section{Pre-cast SDS-PAGE (reducing)}

SDS-PAGE was done by the Invitrogen NuPAGE® System (Invitrogen, Cambridge, UK). Protein samples were incubated with NuPAGE $®$ SDS Sample buffer (Invitrogen) and reducing agent (Invitrogen). The samples were incubated at $95^{\circ} \mathrm{C}$ for $5 \mathrm{~min}$. Prestained low molecular weight marker (Invitrogen) was used as size standard.

NuPAGE® $4 \%-12 \%$ Bis-Tris-HCl gels (Invitrogen) were run at $200 \mathrm{~V}$ and $400 \mathrm{~mA}$ in NuPAGE $®$ MES SDS running buffer (Invitrogen) for approximately $30 \mathrm{~min}$. After electrophoresis, gels were stained with SilverQuest ${ }^{\mathrm{TM}}$ Silver Staining Kit (Invitrogen) according to the manufacturer's instructions.

\section{Biotinylation of SP-A and SP-D}

Proteins (1 mg in 1-2 mL final volume) were dialysed into $0.1 \mathrm{M} \mathrm{NaCl}$, $0.1 \mathrm{M} \mathrm{NaHCO}_{3}, \mathrm{pH} 8.3$ overnight at $4^{\circ} \mathrm{C}$. Biotin stock solution was prepared by dissolving $0.5 \mathrm{mg}$ EZ-Link ${ }^{\mathrm{TM}}$ Sulfo-NHS-SS-Biotin (Pierce, Rockford, IL, USA) in $50 \mu \mathrm{L}$ dimethylsulphoxide (DMSO, Sigma) The protein was incubated with 20 -fold molar excess of biotin at room temperature (RT) for $6 \mathrm{~h}$ in the dark. The biotinylated protein was then dialysed into TBS overnight at $4^{\circ} \mathrm{C}$ in the dark to remove unbound biotin.

\section{Preparation of magnetic beads coated with SP-A and SP-D}

Dynabeads ${ }^{\circledR}$ M-280 Streptavidin (Invitrogen) $(400 \mu \mathrm{L})$ were washed twice in $0.5 \mathrm{~mL}$ TBS by placing the tube on a magnetic particle concentrator (Invitrogen) for 1-2 min and removing the supernatant while the tube remained on the magnet. Solutions of biotinylated SPA or SP-D (200 $\mu \mathrm{g}$ in $200 \mu \mathrm{L}$ TBS plus $1 \mathrm{mM}$ EDTA (TBS/EDTA)) were centrifuged at $9000 \mathrm{~g}$ for $10 \mathrm{~min}$ and absorbance of the supernatant 
was measured at $280 \mathrm{~nm}$ before applying the protein solution to the washed beads. The mixture was incubated for $30 \mathrm{~min}$ at RT with gentle rotation.

After removing and centrifuging the supernatant as stated above, the absorbance was measured again. Binding was indicated when the absorbance of the supernatant decreased markedly. The coated beads were washed twice in $0.5 \mathrm{~mL}$ TBS/EDTA before incubating them for 5 min with $100 \mu \mathrm{L} 100 \mathrm{mM}$ citric acid, $\mathrm{pH} 2.5$ to remove noncovalently-bound protein from the beads. After washing once with $0.5 \mathrm{~mL}$ TBS/EDTA, the beads were re-equilibrated in $0.5 \mathrm{~mL}$ TBS plus $2.5 \mathrm{mM} \mathrm{CaCl} 2$ (TBS/Ca) and stored at $4^{\circ} \mathrm{C}$ for further use.

Binding of the collectins to the beads was verified by SDS-PAGE analysis of the coated beads in comparison to non-coated beads.

\section{Lysis of neutrophils}

Approximately $10^{8}$ cells were harvested and centrifuged for $10 \mathrm{~min}$ at $800 \mathrm{~g}$. After washing with TBS, pellets were resuspended in $1 \mathrm{~mL}$ of TBS/Ca containing $2 \%$ Triton X-100, $10 \mu \mathrm{g} / \mathrm{mL}$ DNase I (Sigma), $10 \mu \mathrm{g} / \mathrm{mL}$ RNase A (Sigma) and $1 / 4$ protease inhibitor cocktail tablet (Roche Diagnostics, Mannheim, Germany). The mixture was incubated for $2 \mathrm{~h}$ at $37^{\circ} \mathrm{C}$. The cell debris was spun down at $9000 \mathrm{~g}$ for $10 \mathrm{~min}$ and supernatants were stored at $-20^{\circ} \mathrm{C}$ for further use.

\section{Isolation of collectin binding proteins from neutrophil cell lysates}

The magnetic beads coated with SP-A or SP-D $(500 \mu \mathrm{L})$ were incubated with $1 \mathrm{~mL}$ of neutrophil cell lysate overnight at $\mathrm{RT}$ in the dark and with gentle rotation. On the following day, the supernatants were separated from the beads, followed by washing $16 \times$ with $0.5 \mathrm{~mL}$ TBS/Ca. Proteins bound in a calcium ion dependent manner were eluted with $2 \times 50 \mu \mathrm{L}$ TBS/EDTA for $5 \mathrm{~min}$ each. Further elution of proteins was performed by incubating the beads with $2 \times 50 \mu \mathrm{L}$ $100 \mathrm{mM}$ citric acid, $\mathrm{pH} 2.5$ for $5 \mathrm{~min}$ each. The supernatants of EDTA and $\mathrm{pH} 2.5$ elutions were centrifuged at $9000 \mathrm{~g}$ for $10 \mathrm{~min}$ to remove contaminating beads before running them on SDS-PAGE.

\section{Western Blotting}

Samples containing the eluates obtained from SP-A and SP-D coated magnetic beads were run reduced on SDS-PAGE. The unstained gel was equilibrated in transfer buffer ( $39 \mathrm{mM}$ glycine, $48 \mathrm{mM}$ Tris- $\mathrm{HCl}$, $20 \%$ methanol, $\mathrm{pH}$ 8.3), then transferred to a PVDF membrane (Millipore Corp., MA, USA) pre-soaked for 10 s in $100 \%$ methanol, 5 min in water and $5 \mathrm{~min}$ in transfer buffer. A semi-dry blotting apparatus (Biometra, Goettingen, Germany) was used and proteins transferred by electrophoresis for $4 \mathrm{~h}, 50 \mathrm{~mA}, 200 \mathrm{~V}$ at RT. The membrane was blocked with TBS plus $0.05 \%$ Tween-20 and $2 \%$ BSA (TBS/Tween/ $\mathrm{BSA}$ ) at $4^{\circ} \mathrm{C}$, washed three times with TBS plus $0.05 \%$ Tween-20 (TBS/Tween) for $5 \mathrm{~min}$ each and incubated for $1 \mathrm{~h}$ at RT with $1 \mu \mathrm{g} / \mathrm{mL}$ anti-MPO mAb (AbD Serotec, Abingdon, UK) in $10 \mathrm{~mL}$ TBS/Tween/ BSA. The membrane was washed three times with TBS/Tween as above and incubated for $1 \mathrm{~h}$ at RT with 1000-fold diluted HRPconjugated rabbit anti-mouse polyclonal antibodies (Sigma) for $1 \mathrm{~h}$ at $\mathrm{RT}$ in $10 \mathrm{~mL}$ TBS/Tween/BSA. After washing three times as above, the membrane was exposed to Enhanced Chemiluminescence Western Blot Detection Reagents (Amersham Biosciences, Amersham, UK) for detection.

\section{ELISA}

Ninty-six-well Maxisorp microtiter plates (Greiner Bio One, Frickenhausen, Germany) were coated with $5 \mu \mathrm{g} / \mathrm{Ml}$ MPO (Sigma) in $100 \mu \mathrm{L}$ TBS and left overnight at $4^{\circ} \mathrm{C}$. Wells were washed three times with $200 \mu \mathrm{L}$ TBS/Tween and blocked with $200 \mu \mathrm{L}$ TBS plus $1 \%(w / v)$ BSA (TBS/BSA) for 30 min at RT. After washing three times again with TBS/Tween, SP-A or SP-D at different concentrations $(10 \mu \mathrm{g} / \mathrm{mL}$ or $20 \mu \mathrm{g} / \mathrm{mL}$ ) were added to each well in $100 \mu \mathrm{L}$ TBS/BSA containing $2.5 \mathrm{mM} \mathrm{CaCl}_{2}$ (TBS/BSA/Ca) or $1 \mathrm{mM}$ EDTA (TBS/BSA/EDTA). After incubating for $1 \mathrm{~h}$ at RT and washing three times with TBS/Tween, bound proteins were detected using biotinylated monoclonal anti-SPA or anti-SP-D antibodies $(1 \mu \mathrm{g} / \mathrm{mL})$ in $100 \mu \mathrm{L}$ TBS/BSA/Ca or TBS/ BSA/EDTA by incubating at RT for $1 \mathrm{~h}$. After washing with TBS/ Tween, $100 \mu \mathrm{L}$ of 200 -fold diluted Streptavidin-HRP (Cat \# S5512, Sigma) in TBS/BSA/Ca or TBS/BSA/EDTA was added to each well, and plates were incubated at RT for $1 \mathrm{~h}$ prior to washing. Finally, $100 \mu \mathrm{L}$ substrate (FAST ${ }^{\mathrm{TM}}$ o-phenylenediamine dihydrochloride tablet set, Sigma) was added to each well and after sufficient color development, the reaction was stopped with $100 \mu \mathrm{L} 1 \mathrm{M} \mathrm{H}_{2} \mathrm{SO}_{4}$. Absorbance values were measured at $492 \mathrm{~nm}$.

\section{Flow cytometry assay of anti-MPO binding}

Viable, early and late apoptotic neutrophils $(500,000)$ in $50 \mu \mathrm{L}$ of TBS/ $\mathrm{BSA} / \mathrm{Ca}$ were incubated with anti-MPO mAb (AbD Serotec, $1 \mu \mathrm{g} / \mathrm{mL}$ final concentration). Cells were washed once in $200 \mu \mathrm{L} T B S / B S A / C a$, followed by simultaneous incubation with FITC-conjugated Rabbit anti-mouse antibodies (100-fold diluted, Sigma), PE-labeled annexin V (20-fold diluted) and 7-AAD (20-fold diluted) in the same buffer. After $1 \mathrm{~h}$ incubation at RT in the dark, the cells were centrifuged and washed once in $200 \mu \mathrm{L}$ TBS/BSA/Ca and fixed with $200 \mu \mathrm{L}$ TBS containing $2.5 \mathrm{mM} \mathrm{CaCl}_{2}$ and $1 \%(v / v)$ Formaldehyde for $15 \mathrm{~min}$ before being measured by flow cytometry.

Inhibition of anti-MPO mAb binding to late apoptotic cells was performed by adding unlabelled SP-A or SP-D in various concentrations to the sample simultaneously with the anti-MPO Ab. All subsequent steps were performed as described above. A decrease of fluorescence in comparison to the sample without SP-A or SP-D indicated inhibition of binding.

Cells were assessed for fluorescence using a FACScan instrument (Becton Dickinson Immunocytometry systems, San Jose, CA, USA). Acquisition and processing of data from 10,000 cells per sample were carried out with the CellQuest software (Becton Dickinson).

\section{Fluorescence microscopy}

Briefly, 500,000 cells were suspended in TBS/BSA and centrifuged at $800 \mathrm{~g}$ for $10 \mathrm{~min}$. The pellet was resuspended in $50 \mu \mathrm{L}$ of the same buffer containing $2.5 \mathrm{mM} \mathrm{CaCl}_{2}$ or $1 \mathrm{mM}$ EDTA. Biotinylated SP-A or SP-D $(10 \mu \mathrm{g}$ in 10-20 $\mu \mathrm{L})$ and anti-MPO $\mathrm{mAb}(\mathrm{AbD}$ Serotec, $1 \mu \mathrm{g} / \mathrm{mL})$ were added before incubating the samples for $1 \mathrm{~h}$ at $\mathrm{RT}$. After spinning at $800 \mathrm{~g}$ for $10 \mathrm{~min}$, the pellet was washed once in $200 \mu \mathrm{L}$ TBS/BSA containing $2.5 \mathrm{mM} \mathrm{CaCl}_{2}$ or $1 \mathrm{mM}$ EDTA, resuspended in $50 \mu \mathrm{L}$ of the same buffer containing PE-labeled streptavidin (200-fold diluted) and FITC-conjugated rabbit anti-mouse Ab (100-fold diluted, Sigma) and incubated for $1 \mathrm{~h}$ in the dark at RT. After washing and fixation of the cells in $200 \mu \mathrm{L}$ TBS containing $\mathrm{CaCl}_{2}$ or EDTA and $1 \%$ $(v / v)$ formaldehyde for $15 \mathrm{~min}$, cells were centrifuged again for $10 \mathrm{~min}$ 
at $800 \mathrm{~g}$. The pellet was dissolved in $20 \mu \mathrm{L}$ ProLong ${ }^{\circledR}$ Gold antifade mounting medium (Invitrogen). Cells were mounted on glass slides, covered with coverslips and cured for $24 \mathrm{~h}$ prior to imaging. Fluorescent cells were observed using a Zeiss Axioskop 2 Plus fluorescence microscope. Images were collected using a Retiga-SRV camera (QImaging, Surrey, Canada).

\section{Identification of proteins by mass spectrometry}

After running SDS-PAGE and silver staining the bands to investigate were excised using a clean scalpel and cut into $1 \mathrm{~mm}$ cubes. Proteins were reduced using $10 \mathrm{mM} \mathrm{DTT}$ for $30 \mathrm{~min}$ at $37^{\circ} \mathrm{C}$ and alkylated with $55 \mathrm{mM}$ iodoacetamide for $60 \mathrm{~min}$ at RT. The reduced and alkylated peptides were digested with trypsin 150 wtwt (Sequence grademodified, Promega, Madison WI, USA) for $16 \mathrm{~h}$ at $37^{\circ} \mathrm{C}$ in $50 \mathrm{mM}$ $\mathrm{NH}_{4} \mathrm{HCO}_{3}, \mathrm{pH} 8.0$ and subsequently desalted on a $\mathrm{C} 18$ packed pipette tip. Samples were injected onto an Ultimate 3000 nano HPLC (Dionex, Sunnyvale, CA, USA) system coupled to Orbitrap mass spectrometer (Thermo Electron, Waltham, MA, USA). Samples were resolved on a $100 \mu \mathrm{m}$ id $/ 5 \mathrm{~cm}$ picotip column (New Objective, Woburn, MA, USA), which was packed in-house with Reprosil-Pur C18-AQ phase (SGE Analytical Science, Milton Keynes, UK). A 40min gradient was used to separate the peptides. The mass spectrometer was operated in a data-dependent acquisition mode. Precursor scans were performed in the orbitrap at a resolving power of 60,000 , from which five precursor ions were selected and fragmented in the linear ion trap. Charge state +1 ions were rejected. Peak lists were generated using DTASuperCharge (Matrix Science, London, UK) and searched using Mascot (Matrix Science). Data were searched against International Protein Index (IPI) database, restricting the taxonomy to human. Carbamidomethyl cysteine was set as fixed modification and oxidised methionine and deamidation of asparagine and glutamine as potential variable modifications. Precursor mass accuracy tolerance was set at $10 \mathrm{ppm}$ and $\mathrm{MS} / \mathrm{MS}$ at $0.5 \mathrm{Da}$.

\section{ACKNOWLEDGEMENTS}

We thank Dr. Benjamin Thomas and the Proteomic Facility at the Dunn School of Pathology, Oxford University, for analytical services. We also thank Dr. Emyr Lloyd-Evans, Dept. of Pharmacology, University of Oxford, for assistance in the generation of fluorescence images. This work was financially supported by the Medical Research Council, UK.

\section{ABBREVIATIONS}

7-AAD, 7-amino-actinomycin D; BALF, broncho-alveolar lavage fluid; $\mathrm{CRD}$, carbohydrate recognition domain; MFI, mean fluorescence; MPO, myeloperoxidase; PE, phycoerythrin; SEM, standard error of the mean; SP-A, surfactant protein A; SP-D, surfactant protein D; TBS, TRIS-buffered saline

\section{REFERENCES}

Audrain, M.A., Baranger, T.A., Moguilevski, N., Martin, S.J., Devys, A., Lockwood, C.M., Muller, J.Y., and Esnault, V.L. (1997). Antinative and recombinant myeloperoxidase monoclonals and human autoantibodies. Clin Exp Immunol 107, 127-134.

Cox, G., Crossley, J., and Xing, Z. (1995). Macrophage engulfment of apoptotic neutrophils contributes to the resolution of acute pulmonary inflammation in vivo. Am J Respir Cell Mol Biol 12, 232-237.

Fadok, V.A., Bratton, D.L., and Henson, P.M. (2001). Phagocyte receptors for apoptotic cells: recognition, uptake, and consequences. J Clin Invest 108, 957-962.

Fadok, V.A., and Chimini, G. (2001). The phagocytosis of apoptotic cells. Semin Immunol 13, 365-372.

Fadok, V.A., and Henson, P.M. (2003). Apoptosis: giving phosphatidylserine recognition an assist-with a twist. Curr Biol 13, R655-R657.

Fadok, V.A., Voelker, D.R., Campbell, P.A., Cohen, J.J., Bratton, D.L., and Henson, P.M. (1992). Exposure of phosphatidylserine on the surface of apoptotic lymphocytes triggers specific recognition and removal by macrophages. J Immunol 148, 2207-2216.

Flemmig, J., Lessig, J., Reibetanz, U., Dautel, P., and Arnhold, J. (2008). Non-vital polymorphonuclear leukocytes express myeloperoxidase on their surface. Cell Physiol Biochem 21, 287-296.

Gaynor, C.D., McCormack, F.X., Voelker, D.R., McGowan, S.E., and Schlesinger, L.S. (1995). Pulmonary surfactant protein A mediates enhanced phagocytosis of Mycobacterium tuberculosis by a direct interaction with human macrophages. J Immunol 155, 5343-5351.

Haagsman, H.P., Elfring, R.H., van Buel, B.L., and Voorhout, W.F. (1991). The lung lectin surfactant protein $A$ aggregates phospholipid vesicles via a novel mechanism. Biochem J 275, 273-276.

Haagsman, H.P., Sargeant, T., Hauschka, P.V., Benson, B.J., and Hawgood, S. (1990). Binding of calcium to SP-A, a surfactantassociated protein. Biochemistry 29, 8894-8900.

Hartshorn, K.L., White, M.R., Tecle, T., Holmskov, U., and Crouch, E. C. (2006). Innate defense against influenza A virus: activity of human neutrophil defensins and interactions of defensins with surfactant protein D. J Immunol 176, 6962-6972.

Haslett, C. (1999). Granulocyte apoptosis and its role in the resolution and control of lung inflammation. Am J Respir Crit Care Med 160, S5-S11.

Holmskov, U., Malhotra, R., Sim, R.B., and Jensenius, J.C. (1994). Collectins: collagenous C-type lectins of the innate immune defense system. Immunol Today 15, 67-74.

Hussain, N., Wu, F., Zhu, L., Thrall, R.S., and Kresch, M.J. (1998). Neutrophil apoptosis during the development and resolution of oleic acid-induced acute lung injury in the rat. Am J Respir Cell Mol Biol 19, 867-874.

Jäkel, A., Clark, H., Reid, K.B., and Sim, R.B. (2010). The human lung surfactant proteins A (SP-A) and D (SP-D) interact with apoptotic target cells by different binding mechanisms. Immunobiology 215 , 551-558.

Klebanoff, S.J. 1991. Myeloperoxidase: occurence and biological function; in Everse, J., Everse, E.K., Grisham, M.B. (eds): Peroxidases in chemistry and biology. Boston CRC Press; pp 1-35.

Kowalczyk, A.P., Bornslaeger, E.A., Norvell, S.M., Palka, H.L., and Green, K.J. (1999). Desmosomes: intercellular adhesive junctions specialized for attachment of intermediate filaments. Int Rev Cytol 185, 237-302.

Kuroki, Y., and Akino, T. (1991). Pulmonary surfactant protein A (SPA) specifically binds dipalmitoylphosphatidylcholine. J Biol Chem 266, 3068-3073.

Lessig, J., Spalteholz, H., Reibetanz, U., Salavei, P., Fischlechner, 
M., Glander, H.J., and Arnhold, J. (2007). Myeloperoxidase binds to non-vital spermatozoa on phosphatidylserine epitopes. Apoptosis $12,1803-1812$.

Michelis, D., Kounnas, M.Z., Argraves, W.S., Sanford, E.D., Borchelt, J.D., and Wright, J.R. (1994). Interaction of surfactant protein A with cellular myosin. Am J Respir Cell Mol Biol 11, 692-700.

Ogden, C.A., deCathelineau, A., Hoffmann, P.R., Bratton, D., Ghebrehiwet, B., Fadok, V.A., and Henson, P.M. (2001). C1q and mannose binding lectin engagement of cell surface calreticulin and CD91 initiates macropinocytosis and uptake of apoptotic cells. J Exp Med 194, 781-795.

Schagat, T.L., Wofford, J.A., and Wright, J.R. (2001). Surfactant protein A enhances alveolar macrophage phagocytosis of apoptotic neutrophils. J Immunol 166, 2727-2733.

Somersan, S., and Bhardwaj, N. (2001). Tethering and tickling: a new role for the phosphatidylserine receptor. J Cell Biol 155, 501-504.

Strong, P., Kishore, U., Morgan, C., Lopez Bernal, A., Singh, M., and Reid, K.B. (1998). A novel method of purifying lung surfactant proteins $A$ and $D$ from the lung lavage of alveolar proteinosis patients and from pooled amniotic fluid. J Immunol Methods 220, 139-149.

Suwabe, A., Mason, R.J., and Voelker, D.R. (1996). Calcium dependent association of surfactant protein $A$ with pulmonary surfactant: application to simple surfactant protein A purification. Arch Biochem Biophys 327, 285-291.

Tino, M.J., and Wright, J.R. (1999). Surfactant proteins A and D specifically stimulate directed actin-based responses in alveolar macrophages. Am J Physiol 276, L164-L174.

Tonks, A., Pearn, L., Musson, M., Gilkes, A., Mills, K.I., Burnett, A.K., and Darley, R.L. (2007). Transcriptional dysregulation mediated by RUNX1-RUNX1T1 in normal human progenitor cells and in acute myeloid leukaemia. Leukemia 21, 2495-2505.

Weber, K., and Osborn, M. (1969). The reliability of molecular weight determinations by dodecyl sulfate-polyacrylamide gel electrophoresis. J Biol Chem 244, 4406-4412.

Wright, J.R., and Youmans, D.C. (1995). Degradation of surfactant lipids and surfactant protein $\mathrm{A}$ by alveolar macrophages in vitro. Am J Physiol 268, L772-L780. 